\title{
Book Flood: A Countermeasure to the Icy Period in English Acquisition
}

\author{
Shuqin Wang ${ }^{1, *}$ \\ ${ }^{1}$ School of Foreign Languages, Shandong University of Finance \& Economics, Ji'nan, Shandong 250014, China \\ *Corresponding author. Email: shuqinw@126.com
}

\begin{abstract}
The "icy period" appearing in the process of English acquisition is caused by the long-term disjunction between the knowledge of English and its application. This paper discusses the icy period from the view of neurolinguistics, psycholinguistics and cognitive linguistics, and puts forward that "book flood", namely a large amount of reading, is an effective strategy to break the "ice". "Book flood" not only creates the acquired environments for English learning but also combines the language knowledge and application. It can improve students' English proficiency by optimizing learning modes, stimulating students' interest and promoting teaching methods.
\end{abstract}

Keywords: English acquisition, Icy period, Book flood.

\section{INTRODUCTION}

Many Chinese students, after learning English for many years, gradually lose their confidence in their English competence, and complain that they spend the most time and get the least results. Repetitive learning cannot help them apply English as freely and beautifully as native speakers, and their English proficiency comes to a standstill. In fact, students of different levels often experience a stagnate phase, which we call the "icy period". That is to say, when students proceed to a certain stage of English learning, they cannot make marked progress anymore as if they were stuck at a certain place and could not make a move, no matter how hard they study and how much time they spend on it.

Many investigations and studies have proved that one of the reasons that cause the standstill in English learning is that the language knowledge is out of line with language application for a long time. Chinese students learn English mainly through classroom teaching and the guiding of reference books, which results in a fixed pattern in language acquisition. They pay more attention to the acceptance of the systematic knowledge and downplay its application, thus leading to the standstill. This situation results from different factors, such as the assessment system, inappropriate teaching methods and students' psychologically cognitive deviation, etc.. This paper discusses this problem from the aspects of neurolinguistics, psycholinguistics, cognitive linguistics, and acquired environment, and puts forward "book flood" as the countermeasure to break the "ice". "Book flood" means reading a large number of English materials, which is an effective strategy to give students impetus and improve their English on the whole.

\section{FORMATION OF THE "ICY PERIOD"}

Modern linguists regard language acquisition as a kind of conditional memory learning, while psychologists organically link language acquisition with the inborn brain mechanism, and think that language is determined by genetic mechanism. The cognitive theorists hold that learning is not a stimulus-response connection, but a process of forming internal cognitive structure and processing information. Learning lies in the change of internal cognition, and it is a much more complicated process than stimulus-response connection. They focus on explaining the intermediate process of learning behavior, that is, the purpose and significance of learning, and think that these processes are the variable factors that control language learning. 


\subsection{Innate Neural Mechanism of Language and Acquired Environment}

The language system is generated by the combination of innate neural mechanism of language and the acquired environment stimulation. Language generation, understanding and production involve in very complex neural mechanisms, and the acquisition is a dynamic process during which the function of cerebral language develops and becomes mature. Language function is closely related to cerebral nerve cells in both hemispheres, and the cerebral language function must be stimulated by acquired environment before becoming mature and perfect. The understanding and production of language refer to the competence of using language, which is restricted by many neural mechanisms. The integrated language competence could be reflected in the ability of internalizing the language system, that is, to generate a manipulating language system in the nerve system. The innate language mechanism of the cranial nerves alone cannot complete the generation process of the internal language system, and it only provides a possibility. It is the language environment that provides the great impetus for the generation of the internal language system.

The acquisition of language competence is closely related to the input and processing of language materials. In China, the environment of teaching and learning English is mainly within the classroom. Hence there is a great imbalance between language input and output. In classroom, especially those large classes, the traditional "whole class teaching" method makes students, to some extent, become passive recipients. Most students and teachers take vocabulary, grammar and language structure as the most important thing in learning English. They believe that the standard to make judgments on a person's English proficiency is the number of vocabulary he can memorize and the correctness of his grammar and sentence structure. Therefore, too much emphasis has been put to memorization. Language learning is regarded as the mathematical formula, only suitable for the purpose of examination. In the long run, that concept is not advisable since it only emphasizes words and structures, lacking the input of social and cultural knowledge, ignoring the importance of applying language knowledge into practice. Students have no chances to actively participate in language activities. They only swallow the knowledge of English language itself without digesting and absorbing it. That is why they can neither give effective language feedback nor properly express themselves. Since the language knowledge is not internalized to be one's own, the complete language competence cannot develop. Gradually, students' language competence lags behind, and it is very difficult for them to make obvious progress in English. As a result, the "icy period" is formed.

\subsection{Positive Transfer and Negative Transfer}

Psycholinguistics, which rose and developed in 1950s, was theoretically based on behavioral psychology. Psycholinguists hold that language learning is a process of constant stimulation and reinforcement. Burrbus Frederick Skinner, the representative of new behaviorism, believed that the key to success in learning lied in giving students appropriate reinforcement. That is, by providing positive reinforcement or removing negative reinforcement, students can maintain their corresponding behavior at a certain level for a long time; by strengthening the reinforcement, students can create more complex behaviors.

In foreign language learning, positive transfer and negative transfer may occur to most learners. Rod Ellis made an analysis on the negative transfer or interference in learning English. He found that in China, in terms of the mother tongue interference in grammar and sentence pattern, the negative transfer took up 59\% of all the unsuccessful factors that influenced the language learners. The worse thing is that Chinese students and teachers mainly focus on students' mastery of vocabulary, grammar and sentence pattern, while ignoring the importance of discourse. And too many tests make students mistake grammar as the only standard to measure a person's English competence.

Moreover, while reading English materials, most students are used to translating them into Chinese for a better understanding; as for writing English compositions, they usually conceive or even write in Chinese first and then translate into English. So the composition is simply made up of the Chinese logical framework with English grammatical rules and words. The writing completed in this way is often full of confusing sentences, failing to express its meaning. Since the English thinking mode is different from that of Chinese, this Chinese-English writing can never become a good article. The writing and reading habits developing over years have led to the fossilization of language and formed an "icy 
period" during English learning, especially among non-English majors.

\subsection{Internal Cognitive Structure and Processing Information}

Cognitive theory holds that there is a thinking process behind human behavior, so the change of behavior is observable. Students' inner activities can be inferred from their behaviors. Therefore, learning is not simply the link between stimulus and response, but the process of forming internal cognitive structure and processing information. The significance of learning lies in the change of internal cognition. Therefore, learning is a much more complicated process than a stimulus-response connection. According to cognitive theories, learning is an active, cumulative, constructive, diagnostic, situational and goal-oriented process. Learning itself does not come into being automatically, but requires a lot of psychological activities, which involves in the attribution of the acquired knowledge, integrating the new knowledge into the existing knowledge system or module.

The competence development is very important since the final goal of education is to make students become excellent designers of themselves, cultivate their learning interest and promote their cognitive activities. Many current studies have revealed that the cultivation of ability does not come from imparting knowledge through teaching, but to promote special cognitive activities through teaching, which the traditional teaching mode cannot give to students. However, most classroom teaching modes are still based on imparting knowledge to students, and less attention is paid to students' participation. Besides, in China, English teaching staff are insufficient and not all of them are highly qualified. As a result, students could not actively and efficiently learn English. After a long time, they feel distasteful and begin to slack off in their studies, which is another factor that causes the formation of the "icy period".

\section{COUNTERMEASURES TO THE "ICY PERIOD"}

Language as the main carrier of culture has social attributes, and its development is greatly influenced by the norms of human communities. Different languages are not only different in sounds, shapes and patterns but also in thinking modes. In order to prevent the formation of "icy period" or to break the "icy period" in English learning, we should not only solve the problem that the knowledge and application of language come apart, but also overcome the effect coming from the thinking mode of the mother tongue. "Book flood", which means reading a large number of English materials, may be a good method to solve these problems. "Book flood" is also a necessary way to develop students' intelligence and capability. Students' ability to synthesize and analyze information and to absorb and apply new knowledge can only be acquired after a large amount of reading practice.

\subsection{Book Flood: Basing on Acquired Environment Theory}

The acquired environment theory of language learning is based on Ivan Pavlov's classical theory on the conditioned response and two kinds of signal systems and Watson's behaviorism theory. It can be divided into three types: imitation theory, reinforcement theory and intermediary theory. This theory emphasizes that the acquired environment of learning plays a decisive role in language acquisition

The acquired environment theory thinks that in terms of the development of an organism, the most important thing is not those innate factors, but the acquired experience. The early part of this theory is based on the stimulus-response theory of behaviorism, which holds that language symbolizes a set of behavioral habits, and the process of language acquisition equals the process of forming such behaviors. Second language acquisition needs to continuously overcome the interference of the habits of mother tongue and at the same tome cultivate new language habits. The acquired environment theory proposed a new "Ac-culturation Model". According to this theory, during the second language learning process, learners are often influenced by the social and psychological distance from native speakers. Social distance refers to the estrangement between learners' community and the community who speak the target language; psychological distance refers to the influencing factors in terms of learning individuals. These social and psychological variables constitute an important factor in second language acquisition, namely "cultural transfer", referring to the process that learners adapt to a new culture. The transfer degree determines the quality of their second language acquisition. 
Considering this theory, "book flood" can be the shortcut to complete the "cultural transfer". The phrase comes from the Iceland national tradition. In Iceland, the best Christmas gift is a book. Icelanders own more books per capita than that in any other country in the world, and here most of the books are published and sold from late September to early November, which is named Jolabokaflod, translated to the "Christmas Book Flood." We use the phrase "book flood" to mean reading lots of English materials in order to make an acquired environment for language learning and to greatly improve students' English within a short time.

\subsection{Book Flood: Helping Students to Think in English}

Massive reading is an effective way to learn English thinking mode because it creates an acquired environment of language learning. As we all know, language can be naturally obtained as long as a learner is in a natural language environment. However, in China, there is no English environment. In this situation, increasing the reading quantity is the best way for English students to immerse themselves in the English environment. Continuous reading English can develop and cultivate students' thinking mode in English and remove the influence of Chinese thinking pattern. Only in this way can the communication in English go on smoothly. As Edward Hall, an American anthropologist, said: "There are two major obstacles in understanding. One is the straightness of language. The other is the obstacles contained in various cultures and the deep prejudice caused by them."

A large amount of reading not only converts students' thinking modes but also enables them to surmount the barriers of cultural differences between the East and the West. Through reading, students enlarge their vocabulary, broaden their knowledge, understand western social culture, and eliminate unfavorable factors caused by cultural differences. In the process of reading, because students integrate themselves into the atmosphere of English language, they gradually develop English thinking modes and can write and speak in the same style as native speakers. Take the relationship between reading and writing as an example, there is an internal connection between them, and they can be transformed to each other. Reading is the transformation from the external written language to the internal language, while writing is the transformation from the internal language to the external written language. Reading and writing can complement and promote each other and improve together. Delven Schubert said in Creative Wisconsin that communication skills between reading and writing were closely related. Reading enriches our own experiences and thoughts; writing enriches other people's experiences and thoughts. Reading is writing, and writing is reading. Massive reading can help students accumulate knowledge, master language skills and cultivate language sense, so as to improve their English proficiency.

The reading quantity is closely related to English proficiency. "Book flood" emphasizes that the amount of reading materials should be large, otherwise it is not helpful. As we all know, writing and speaking are regarded as output, while reading and listening are input. The more input a student receives, the better his output is likely to be. As Du Fu's poem says:" Ample reading produces fluent writing." Without "ample reading", there would be no "fluent writing". Only after being immersed in "book flood" can students leap over the "icy period" and obtain the desired achievements.

\subsection{Book Flood: Cultivating Interest in English}

Many students experience the icy period and lose their interest in English in the process of learning because though they work hard, their English is still very poor. The reason why students' listening comprehension is poor is not only because they lack listening practice but also because their vocabulary is too small to understand the materials and their knowledge is too narrow. In order to improve listening comprehension students must broaden their knowledge and enlarge vocabulary, which depends on the reading amount. Similarly, a vast amount of reading is a prerequisite for speaking and writing.

"Book flood" not only requires students to read in large quantities, but also read in a wide range. Reading materials may cover a large range with various subjects, including literature, history, important figures, geography, economics, politics, military, culture, folk-custom and other fields, and the genres should be diversified, such as narrative, essay, poetry, biography and speech, etc.. What's more, the reading materials should be carefully selected because the language should be highly qualified, correct and classic, and there should be sufficient vocabulary in the materials. When students chose those they prefer to read, their 
interest in learning English will be greatly aroused. In this way, students can not only learn a lot from reading but also regard reading as a great joy, not a heavy burden.

In addition, in terms of language learning, learners' cultivation is a great motive force, which plays an inestimable role in their progress and has a potential function in alleviating the appearance of icy phenomenon. Massive reading can also improve students' comprehensive quality. It is one of the aims for foreign language learners to bridge the cultural gap between different countries, develop an international outlook and improve the transnational cultivation. Since different nations and countries have their own unique characteristics, foreign language learning can help students understand and become familiar with various cultural phenomena, daily habits and customs, eliminate transnational cultural conflicts, and cultivate their own perspectives. At the same time, ample reading can also strengthen students' aesthetic competence, develop their appreciation and creativity of beauty, which may also stimulate students' interest and minimize language fossilization and melt the "ice" appearing in language learning.

\subsection{Book Flood: Improving Teachers' Quality}

Education is a two-way process. To create a good environment and favorable conditions for language learning, we should not only pay attention to students' learning methods, but also attach importance to teaching methods, so as to develop students' ability of autonomic learning. In the process of teaching, though teachers try their best to guide students to learn various skills of listening, speaking, reading and writing, however, a considerably large number of students cannot make marked progress in improving any of these abilities, not to say the whole English level. One of the main reasons is because of the improper teaching concepts and methods. Ample reading is of great help in broadening teachers' minds and updating their teaching concepts. Reading makes it possible for teachers to adopt a brand-new teaching mode and reevaluate the traditional teaching mode, which regards teachers as the subjects and students as the objects. In the new teaching method, one of the teacher's tasks is to guide students to read. Teachers should compile or select interesting and meaningful English materials, and the materials should be neither too difficult nor too easy. Otherwise, students do not have interest and cannot achieve good results. Meanwhile, teachers can supervise and promote the result of reading practice.

Besides, ample reading can improve teachers' competency and ability in information processing, that is, increasing teachers' ability to use information to assist their teaching. As foreign language teachers are the disseminators of knowledge, the researchers of the teaching materials as well as the designers of the teaching process. Therefore, it is essential for teachers to adapt to the new age, adopt modern tools and methods skillfully in teaching English. Reading can make teachers more confident in designing classroom activities, implementing plans and monitoring the learning process. If teachers improve and enrich their teaching methods and class room activities, students' learning interest and efficiency would be greatly stimulated. Consequently, the "icy period" could be avoided.

\section{CONCLUSION}

In China, there is an old saying: "The best way of learning is to read books". Learning English is no exception, especially for the adults. Reading is the most reliable method for acquiring language, enhancing language sense and expanding knowledge, and the reading quantity and quality is very important. "Book flood" is fit for Chinese students because it allows them to be constantly immersed in the atmosphere of learning English, thus making up the weakness that China has no natural environments to learn English. In reading, students can accumulate experience, convert their thinking modes and improve the sense of English. Although we have explained the problem of the "icy period" in English learning and put forward "book flood" as a good strategy to overcome it, there are still many in-depth and specific problems to be discussed in the future.

\section{AUTHORS' CONTRIBUTIONS}

This paper is independently completed by Shuqin Wang.

\section{REFERENCES}

[1] Ellis, R. Understanding Second Language Acquisition. Oxford: Oxford University Press, 2015.

[2] Ellis, Rod. "Second language acquisition, teacher education and language pedagogy." 
Language Teaching, vol. 2, no. 43, pp. 182$201,2010$.

[3] Ivan Petrovich Pavlov. Complete Works of Pavlov, translated by Zhang Renhua, People's Medical Publishing House, 1959.

[4] Pavlov, I. P. "Conditioned Reflexes: An Investigation of the Physiological Activity of the Cerebral Cortex." Translated and Edited by G. V. Anrep. London: Oxford University Press, 1927.

[5] Shuell, T. J. "The role of the student in learning from instruction." Contemporary Educational Psychology, no. 13, pp. 276-295, 1988.

[6] Skinner, B. "The reinforcing effect of a differentiating stimulus." Journal of General Psychology, no. 14, pp. 263-78, 1936.

[7] Spelunker L. "Interlanguage." International Review of Applied Linguistics, no. 10: pp. 209-31, 1972. 